\title{
Hyperthyroidism with periodic paralysis, acropachy, pre-tibial myxoedema, transient atrial fibrillation and myopathy
}

\author{
R. GUAN \\ M.R.C.P. (U.K.) \\ J. S. CHEAH \\ M.D., F.R.A.C.P.
}

University Department of Medicine (I), Singapore General Hospital, Singapore 0316

\begin{abstract}
Summary
A case of thyrotoxicosis presenting with periodic paralysis and later complicated by acropachy, pretibial myxoedema and transient atrial fibrillation is described. This association has not been reported previously. Possible aetiological links are discussed.

\section{Introduction}

Periodic paralysis, idiopathic atrial fibrillation, acropachy, manic depressive illness, skeletal manifestations, pernicious anaemia and pre-tibial myxoedema have all been separately reported in association with thyrotoxicosis. It is very unusual to encounter a patient with many of the complications. In Singapore thyrotoxic periodic paralysis is relatively common (6.0\% of all thyrotoxics) while pre-tibial myxoedema is rare $(0.7 \%$ of all thyrotoxics). The association of the two conditions in a patient has not been described previously. We report in this paper a patient with hyperthyroidism presenting with periodic paralysis who subsequently developed acropachy, transient atrial fibrillation, pre-tibial myxoedema and myopathy.
\end{abstract}

\section{Case report}

A 48-year-old Chinese man presented in February 1973 with sudden onset lower limb weakness after a heavy meal and had had to be carried to a hospital.

Examination revealed a thin, anxious man with typical signs of hyperthyroidism: lid retraction of both eyes with no periorbital swelling, warm moist hands with fine finger tremors, nail dystrophy but no clubbing, slightly enlarged thyroid gland with no bruit and no evidence of tracheal compression (Fig. 1). He had evidence of lower limb proximal muscle weakness but not other findings were evident in the locomotor system. Cardiorespiratory system and abdomen were normal.

Laboratory investigations confirmed thyrotoxicosis with a serum tri-iodothyronine (T3) uptake of $175 \%$

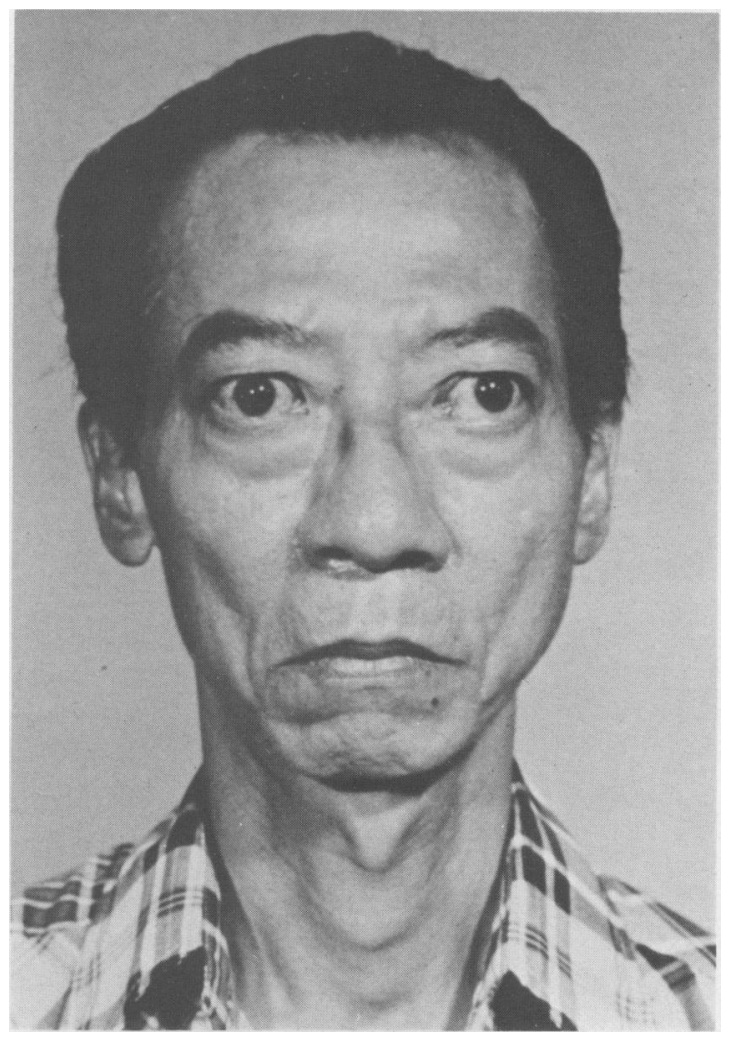

FIG. 1. The patient on initial presentation

(normal 75-115), thyroxine (T4) $9.6 \mu \mathrm{g} / \mathrm{dl}$ (normal: 3-7), free thyroxine index $16 \cdot 8$ (normal: $2 \cdot 25-8 \cdot 05$ ). His serum potassium was low $(3.1 \mathrm{mmol} / \mathrm{litre})$ on admission but became normal with potassium supplements. Anti-thyroglobulin and anti-microsomal antibodies were absent. He was treated with radioiodine $\left(7 \mathrm{mCi}{ }^{131} \mathrm{I}\right)$ and was euthyroid a month later with no further episodes of leg weakness.

Ten months after his initial presentation he was noted to be mildly clubbed. He failed to turn up for 
review 12 months after admission only to be re-气 admitted 4 months afterwards because of relapse $\frac{Z}{\square}$ thyrotoxicosis with increasing weakness in all 4 limbs over a 48-hr period.

Clinical examination revealed an obviously thyro- $\vec{F}$ toxic man. His thyroid gland had not increased in? size but a bruit could be heard over the slightly bigger $\frac{}{C}$ right lobe. He had bilateral exophthalmos with $\frac{\bar{c}}{\bar{c}}$ diplopia on looking to the left and upwards. Clubb- $\vec{\nabla}$ ing of the fingers with tremors were noted. His toes $\varrho$ were also clubbed (Figs. 2 and 3). His limbs werew generally weak (MRC Grade 3/5) especially over the $\vec{\circ}$ proximal musculature. Some rough nodular swellings were noted over his shins (Fig. 4). His serum T3 $\vec{\omega}$ uptake was $170 \%$, T4 $8.0 \mu \mathrm{g} / \mathrm{dl}$ and free thyroxine index 13.6 . Serum potassium was low at $3.0 \mathrm{mmol} / 0$ litre. Other biochemical investigations (calcium, phosphate, magnesium, muscle enzymes, immuno- $\infty$ globulin levels) were normal and antithyroid anti- $\infty$ bodies (anti-thyroglobulin and antimicrosomal) were $\stackrel{N}{G}$ absent. An electromyogram showed myopathic $ᄋ$ changes in his proximal muscles with normal motor ${ }^{\circ}$ nerve conduction. X-ray of hands and forearms failed to show any periosteal elevation and biopsy of $\vec{\longrightarrow}$ the nodular areas showed typical lesions of pre-tibial myxoedema.

Oral potassium supplements and carbimazole were started. His diplopia and weakness improved withoa $\varphi_{\infty}$ mild residual proximal weakness. He was discharged! ${ }^{0}$ with no improvement of his clubbing or skin lesiofs

He became euthyroid a few months later and

FIG. 2. Finger clubbing antithyroid therapy was discontinued 10 months after $\frac{}{0}$ his relapse. His clubbing, however, was noted to be

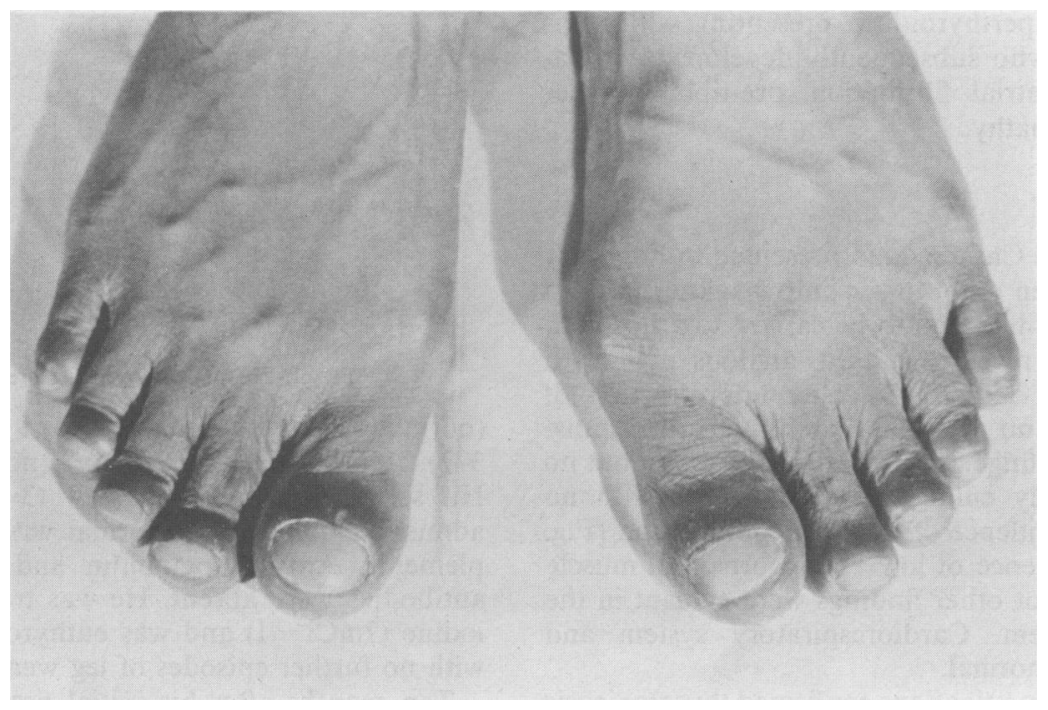

FIG. 3. Clubbing of the toes 


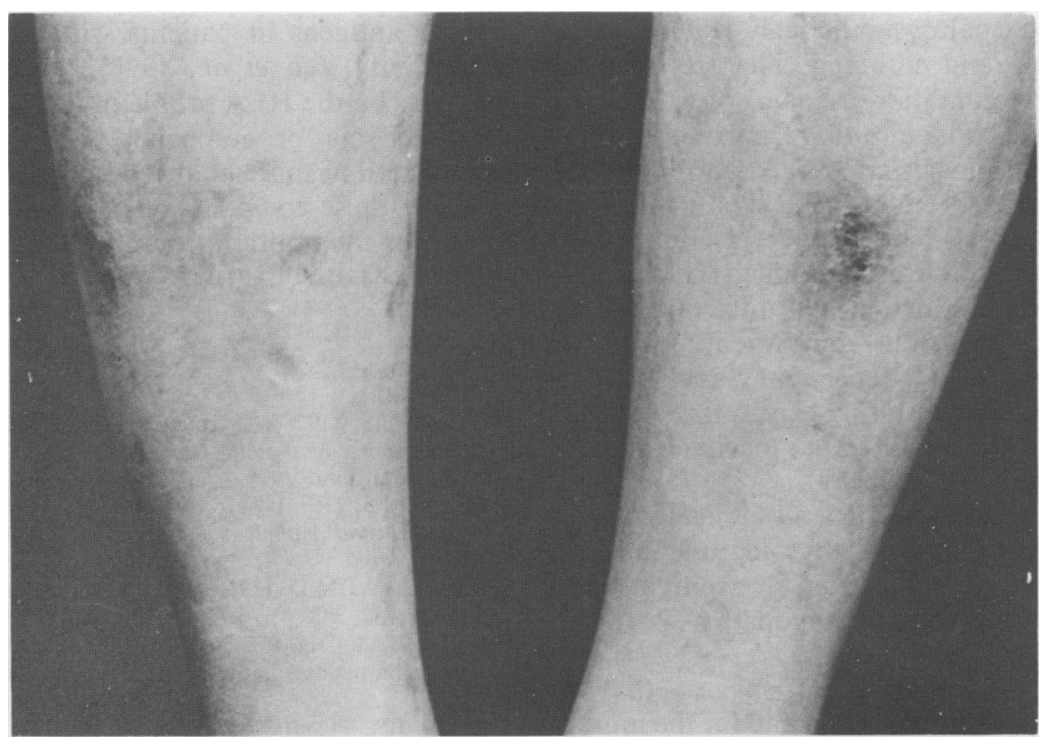

FIG. 4. Pretibial myxoedema

more gross. Repeat chest X-ray and hand X-ray failed to reveal any abnormalities.

He was re-admitted 6 months later in March 1976 with another episode of sudden generalized weakness. He was now in atrial fibrillation with a ventricular response of about $120 / \mathrm{min}$. There were no finger tremors but clubbing was obvious. His thyroid gland was small and firm with no bruit heard. His limbs were very weak (MRC Grade 2/5) especially over the proximal musculature with minimal muscle wasting. The rough areas over his shins were still present.

Biochemical investigations confirmed thyrotoxic periodic paralysis; his serum potassium was 1.9 mmol/litre, T3 uptake $146 \%$, thyroxine $12.4 \mu \mathrm{g} / \mathrm{dl}$, free thyroxine index 18.4 and electrocardiogram showed atrial fibrillation.

Oral potassium supplements were restarted and he was given a second dose of radioactive iodine $\left(10 \mathrm{mCi}{ }^{131} \mathrm{I}\right)$ after which his muscle power improved with residual mild proximal weakness. His atrial fibrillation was transient and he converted to sinus rhythm two days later with a rate of $85 / \mathrm{min}$.

He remained euthyroid both clinically and biochemically. His skin lesions gradually subsided but his finger clubbing remained and became more gross. Repeated chest X-rays to date have failed to reveal any lung pathology. He was euthyroid when last seen in March 1981.

\section{Discussion}

Periodic paralysis is a well-known although not a common complication of thyrotoxicosis, except amongst the Chinese, Japanese and a few other ethnic groups (Cheah, 1978; Minns, Newlin and Day, 1978). The incidence amongst Chinese in Singapore was found to be 6.0\%: $19.2 \%$ in male Chinese and $0.3 \%$ in female Chinese (Cheah, 1974). There have been reports of the familial occurrence of thyrotoxic periodic paralysis (Yueng and $\mathrm{Au}, 1978$ ) and it has been suggested that the racial predilection to this condition for Chinese, Japanese and other mongoloid races is genetically determined and that patients affected share similar HLA antigens such as $\mathrm{A}_{2} / \mathrm{BW}_{22}$ and $\mathrm{AW}_{19} / \mathrm{B}_{17}$ (Yeo et al., 1978). It appears that thyrotoxicosis unmasks the defect by an increased release of insulin to carbohydrate ingestion causing the shift of potassium into muscles thereby causing hypokalaemia and resultant muscular paralysis (Cheah, 1974). Our patient's HLA profile was $\mathrm{A}_{2} \mathrm{BW}_{22}$, there was no family history of hypokalaemic periodic paralysis.

The incidence of thyrotoxic pre-tibial myxoedema in Singapore was found to be $0.7 \% ; 1.6 \%$ in males and $0.3 \%$ in females (Kee and Cheah, 1975). Gimlette (1960) found a higher percentage of its incidence. Pre-tibial myxoedema has also been associated with finger clubbing and exophthalmos.

Our patient is unusual in that he presented with 
thyrotoxic periodic paralysis and later developed pretibial myxoedema and clubbing. The precise aetiology of these three conditions remains obscure and it has been suggested that pre-tibial myxoedema and clubbing are due to localized antigen-antibody reaction (Kriss, Pleshakor and Chien, 1964). Kriss and co-workers suggested that local destruction of the thyroid gland caused release of antigen which would stimulate antibody production. The antigen-antibody complex resulting from this could then get fixed to the leg tissue because of dependency and the local inflammatory reaction resulting causes the condition of pre-tibial myxoedema. A similar mechanism could explain the clubbing (acropachy).

Recent work has shown that all clinically thyrotoxic patients with abnormal thyroid function tests show evidence of myopathy on electromyography although not all show clinical myopathy (Puvanendran et al., 1979).

There is no evidence yet to suggest that an immunological reaction is responsible for the muscular complications of thyrotoxicosis although this mechanism cannot be excluded completely. Instead these complications have been thought to be due to the physiological effect of excessive thyroid hormone on the muscles (Ramsay, 1966; Satoyoshi, Murakami and Torin, 1963).

Another unusual aspect of our patient's condition was that he showed a rather rapid response to his first dose of radio-iodine, being euthyroid after one month, only to relapse over a year later. The reason for this is not known. Perhaps there is an association between this and his multiplicity of complications.

Thyrotoxicosis is a relatively common disease. Why is it that the above complications occur rarely? Genetical susceptibility to their predisposition might be partially responsible as suggested by studies on
HLA antigens in patients with thyrotoxic periodic paralysis (Yeo et al., 1978). There are no similar studies on the HLA profile of patients with pre-tibial $\cong$

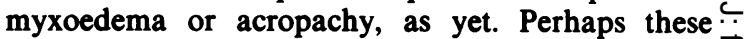
might tell us more about the aetiology and pathogen- $\overrightarrow{\vec{F}}$ esis of these complications and provide an explana- $\overrightarrow{0}$ tion for the multiple complications of thyrotoxicosis $\frac{\square}{0}$ that our patient suffered.

\section{References}

CHeAH, J.S. (1978) Thyrotoxic periodic paralysis in Singapore. $\vec{\circ}$ Proceedings of the 6th Asia and Oceania Congress in Endocrino- $\overrightarrow{\vec{H}}$ logy, Singapore 1978, 1, 282. Eurasia Press, Singapore.

CHEAH, J.S. (1974) Thyrotoxic periodic paralysis in Singapore. $A$ clinical and pathological study. M. D. thesis, University of Singapore.

GiMLETTE, T.M.D. (1960) Pre-tibial myxoedema. British Medical "ैं Journal, 2, 348.

KEE, L.W. \& CHEAH, J.S. (1975) Thyrotoxic pre-tibial myxoedema in Asian patients in Singapore. Postgraduate Medical Journal, 51, 407.

Kriss, J.P., Pleshakor, V. \& ChIEN, J.R. (1964) Isolation and identification of the long acting thyroid stimulator and its relation of hyperthyroidism and circumscribed pre-tibial myxoedema. $\frac{}{\partial}$ Journal of Clinical Endocrinology and Metabolism, 23, 215.

MinNS, G., Newlin, N.S. \& DAY, H. (1978) Hyperthyroidism and periodic paralysis. Hypokalaemia in black patient. Journal of the Kansas Medical Society, 79, 509.

Puvanendran, K., Cheah, J.S., Naganathan, N. \& Wong, P.K. (1979) Thyrotoxic myopathy, a clinical and quantitative analyg్ $c \overrightarrow{0}$ electromyographic study. Journal of the Neurological Sciences, $\$ 2, \infty$ 441.

RAMSAY, I.D. (1966) Muscle dysfunction in hyperthyroidis Lancet, ii, 931.

Satoyoshi, E., Murakami, K. \& Torin, J. (1963) Thyrotoxic myopathy. Lancet, ii, 843.

Yeo, P.P.B., Chan, S.H., Lui, K.F., WeE, G.B., Lim, P. \& Cheah, ฏ J.S. (1978) HLA and thyrotoxic periodic paralysis. British Medical $\stackrel{\square}{\triangle}$ Journal, 2, 930.

YEUNG, R.T.T. \& AU, K.S. (1978) Proceedings of the 6th Asia and $\overline{\bar{O}}$ Oceania Congress of Endocrinology. Singapore 1978, 1, 300. Eurasia Press, Singapore. 